\title{
Developmental trajectories of overweight and obesity of US youth through the life course of adolescence to young adulthood
}

This article was published in the following Dove Press journal:

Adolescent Health, Medicine and Therapeutics

28 March 2012

Number of times this article has been viewed

\section{Xinguang Chen \\ Kathryn Brogan}

Pediatric Prevention Research Center, Wayne State University School of Medicine, Detroit, MI, USA
Correspondence: Xinguang Chen Pediatric Prevention Research Center at Wayne State University, 4707 St Antoine St, Suite W534, Detroit, MI 4820I, USA

$\mathrm{Tel}+\mathrm{I} 3137548663$

Fax +I 3137454993

Email jimchen@med.wayne.edu
Objective: To detect subgroups with different risks at different ages to develop overweight and obese during the adolescence-young adulthood period.

Design: Accelerated longitudinal design and developmental trajectory analysis were used. The likelihoods to become overweight (body mass index [BMI] $>25 \mathrm{~kg} / \mathrm{m}^{2}$ ) and obese (BMI $>30 \mathrm{~kg} / \mathrm{m}^{2}$ ) were assessed across the life course from the ages of 12 to 28 years.

Subjects: Adolescent participants aged $12-17$ years $(n=4119)$ identified in the National Longitudinal Survey of Youth 1997 at baseline were followed up to 2008.

Results: Seven overweight risk groups (WG) were detected for male and female samples respectively, of which five were closely related to each of the following five periods: (a) middle-school ages (19.7\% and $12.6 \%$ for male and female, respectively), (b) high-school ages (11.4\% and $13.6 \%$, respectively), (c) college ages (12.6\% and $9.1 \%$, respectively), (d) post-college ages (11.8\% and $10.0 \%$, respectively), and (e) work-family-formation ages ( $11.0 \%$ and $12.9 \%$, respectively); two were nonperiod-specific groups: a permanent low-risk group for both sexes ( $27.3 \%$ for male, $36.4 \%$ for female), a growing-risk group for males $(6.2 \%)$, and a self-limiting risk group for females $(5.4 \%$, with the likelihood increasing with age, which peaked at the age of 21 years, and then declined). Likewise, six obesity risk groups (OG) were detected, of which four corresponded to the first four high-risk WG groups. The risk groups were relatively independent of race and educational attainment.

Conclusions: Findings of this study imply that five risk groups for weight gain like five consecutive "tests" exist from middle-school period to work-and-family formation. Failure to pass any of these tests in the life course could lead to overweight or obese status. Further research needs to study life-course-specific factors and mechanisms for more effective weight control. Keywords: developmental trajectory, overweight, obesity, adolescents and young adults, life course, United States

\section{Introduction}

Excess weight gain, including overweight and obese among young people, remains a public health challenge that heavily drains limited economic resources. ${ }^{1-5}$ Accumulation of extra fat in the body is associated with a number of diseases, such as type 2 diabetes mellitus, hypertension, and other cardiovascular diseases. ${ }^{3,6-8}$ Obesity alone is estimated to be responsible for 54,000 to 170,000 extra deaths per year in the United States, particularly deaths from cardiovascular diseases. ${ }^{8-10}$

Adolescence to young adulthood represents a transitional period pivotal in the life course for extra weight gain. This period is characterized with dramatic biological, psychosocial, and behavioral changes that often occur at high and unevenly paced speeds. ${ }^{1-13}$ In addition to physical development, a person in this period typically 
completes a number of important tasks expected or required by society, including formal education, employment, and family formation. ${ }^{14,15}$ Each of these may present multiple opportunities for different types of risk factors to operate and promote accumulation of extra fat in the body. ${ }^{12,16-18}$ The impact of race/ethnicity and education may also manifest during this period, with persons of minority status and lower education levels being at greater risk for excess fat. ${ }^{11,19}$ Furthermore, weight gain itself in early periods represents a risk factor for overweight and obesity later in life..$^{20,21}$ Therefore, detecting subgroups at different times and identifying patterns for weight gain across adolescence-young adulthood is of great significance for further etiological and prevention research.

Heterogeneity in weight gain over the life course is emerging as a new focus in research, prevention, and treatment of overweight and obesity. Cross-sectional studies with emphasis on specific developmental periods (eg, early childhood, later childhood, and adulthood) represent a common methodology to acquire data regarding period-specific risks in the life course. ${ }^{22,23}$ However, this cross-sectional design cannot separate the effect of an observed factor from the effect "carried over" from a previous age/period (ie, overweight children maintaining as overweight in adolescence), ${ }^{20,21}$ as well as the effect of birth year or "cohort effect". 1,17,24 Longitudinal studies have been used to investigate changes in bodyweight across various age ranges from childhood to adulthood using conventional growth modeling methods. ${ }^{25-28}$ This type of analytical approach assumes the existence of a single developmental curve for the study population, ignoring potential diversities in the pattern of weight gain over time, as indicated by research findings from published studies. ${ }^{29-32}$

Detecting subgroups with distinctive trajectories in weight gain represents a relatively new approach to investigate lifecourse related risks. With seven years (1997-2003) of body mass index (BMI) data derived from the National Longitudinal Survey of Youth 1997 (NLSY97), a study detected four subgroups with distinctive developmental trajectories: (a) the high-risk group (4.3\%) with mean BMI $>30$ at the age of 12 years, (b) the moderate-to-high risk group (15.9\%) with mean BMI $>25$ after 12 years and $>30$ at 18 years, (c) the low-to-moderate risk group (35.6\%) with mean BMI $>25$ at 20 years, and (d) the low-risk group (44.1\%) with mean BMI varying below 25. ${ }^{31}$ Four subgroups with distinctive BMI trajectories were also detected in another study using panel data from the National Longitudinal Survey of Youth 1979 that covered US adults aged 18 to 49 years old: (a) the earlyadulthood obese group (4.2\%) with mean BMI $>30$ at about
19 years old, (b) the later-adulthood obese group (19.7\%) with $\mathrm{BMI}>30$ at 30 years, (c) the overweight group (41.2\%) with BMI $>25$ at about 29 years, and (d) the normal weight group (35.0\%) with BMI varying from 20 to $25 .{ }^{29}$ Similar results were also reported in other studies that modeled BMI using this approach. ${ }^{17,32}$

Although findings from the studies described above are promising, the techniques employed in these studies depend on the assumption of the existence of an average BMI curve for individual subgroups. However, findings from these studies clearly indicate even within a "homogeneous" subgroup, the BMI measures of the individual participants crossed the lines for overweight/obese at different times/ ages. Consequently, additional subgroups with distinctive trajectories may exist, but not be detected using this methodology as implied from the study findings we described previously. ${ }^{29,31,32}$ Even though these studies targeted populations from childhood to adulthood and used data from different sources, the number of BMI subgroups is limited with no explicit linkages to specific life-course periods.

The goal of this study was to detect subgroups related to specific developmental stages in life course with distinctive trajectories of weight gain. Panel data from a national representative sample of youth transitioning from 12 years old through to 28 years old were analyzed. Instead of directly modeling BMI, we modeled the likelihood of becoming overweight and obese during the 17-year period using the same BMI data. We hypothesized the existence of subgroups whose likelihood to become overweight and obese along with age shows distinctive trajectories corresponding to the main changes in life course across the adolescence-emerging adulthood period.

\section{Methods}

\section{Data source, participants, and longitudinal design}

Data were derived from the NLSY97. Sponsored by the US Department of Labor and based on a national random sample, the NLSY97 recruited subjects aged 12-16 years old by the end of 1996. Data collection was started in 1997. Data were collected by trained staff at the participants' home using the computer-assisted personal interview (CAPI) method. Participants were followed up annually after the baseline survey in 1997. Data from the baseline to the most recent 2008 survey (12 rounds) were used. Among the total 6748 participants of the survey, the 4119 (61.0\%) who completed all 12 waves of the survey and provided completed data were included. Our analysis indicated no 
significance between the participants included in the analysis and the participants lost to follow-up in key variables at the baseline, including BMI (21.8 vs 21.7; $P>0.05)$ and the ethnic compositions. Significantly more females than males were retained at the 12th round of survey in 2008 (64.2\% vs $58.0 \% ; P<0.01)$. Since we conducted our analysis by sex, potential selection bias due to this differential attrition by sex was minimized. The NLSY97 included a complementary sample of ethnic minorities. To obtain data representing the US population, data for this subsample were excluded.

With the NLSY97 data, a longitudinal design was devised. This was achieved by rearranging the participants according to the age at survey at each wave of assessment (see Table 1). With this design, the youngest age group of the participants at the starting year of NLSY97 was 12 years old (the first number in the column under the year of 1997 in Table 1); the oldest who was 17 years old in 1997 advanced to 28 years old in 2008 (the last number in the column under year 2008; Table 1). This design makes it possible to investigate changes from adolescence through young adulthood to cover such important life events as employment and family formation which typically occurs during this period ${ }^{33}$ and may have affected weight gain.

\section{Measurement of overweight and obese}

To model the likelihood to become overweight and obese, overweight was defined as BMI $>25\left(\mathrm{~kg} / \mathrm{m}^{2}\right)$ and obese as
BMI $>30\left(\mathrm{~kg} / \mathrm{m}^{2}\right)$ respectively; and BMI was computed as the ratio of body weight (in kilograms) over squared body height (in meters). Participants in our analysis ranged from 12 to 28 years old, and we acknowledge the use of adult cutoff points of BMI $>25\left(\mathrm{~kg} / \mathrm{m}^{2}\right)$ for overweight and BMI $>30\left(\mathrm{~kg} / \mathrm{m}^{2}\right)$ for obese.

\section{Demographic and other influential variables}

The age of individual participants was computed based on data from the recorded survey date (month, date, and year) and the reported date of birth (month, date, and year) using the SAS macro (SAS Institute, Cary, NC):

\%macro age(date,birth);

floor ((intck('month',\&birth,\&date)-

$($ day $(\&$ date $)<$ day $(\&$ birth $))) / 12$ )

$\%$ mend age;

The calculated age was normalized (minus its mean and divided by its standard deviation) before it was used in trajectory modeling analysis. The normalization is required to avoid collinearity among the variables derived from age, including age ${ }^{2}$ and age ${ }^{3}$ that were needed to detect polynomial trajectories with high order (quadratic, cubic) models.

Sex (male and female), race/ethnicity (non-Hispanic White, non-Hispanic black, Hispanic, and others) were assessed using self-reported data. In addition to describing

Table I Longitudinal design using 12 round data (1997-2008) from the National Longitudinal Survey of Youth 1997 (NLSY97)

\begin{tabular}{|c|c|c|c|c|c|c|c|c|c|c|c|c|c|}
\hline Age & 1997 & 1998 & 1999 & 2000 & 2001 & 2002 & 2003 & 2004 & 2005 & 2006 & 2007 & 2008 & Tota \\
\hline 12 & 564 & & & & & & & & & & & & 564 \\
\hline 13 & 871 & $4 I$ & & & & & & & & & & & 912 \\
\hline 14 & 892 & 827 & 47 & & & & & & & & & & 1766 \\
\hline 15 & 831 & 898 & 863 & 19 & & & & & & & & & 2611 \\
\hline 16 & 686 & 854 & 885 & 826 & 21 & & & & & & & & 3272 \\
\hline 17 & 269 & 801 & 880 & 904 & 838 & - & & & & & & & 3692 \\
\hline 18 & 6 & 643 & 757 & 845 & 892 & 865 & 43 & & & & & & 4051 \\
\hline 19 & & 55 & 650 & 784 & 837 & 885 & 841 & 22 & & & & & 4074 \\
\hline 20 & & & 37 & 674 & 808 & 861 & 907 & 849 & 35 & & & & $4|7|$ \\
\hline 21 & & & & 67 & 661 & 793 & 850 & 890 & 854 & 62 & & & 4177 \\
\hline 22 & & & & & 62 & 673 & 787 & 852 & 898 & 855 & 99 & & 4226 \\
\hline 23 & & & & & & 42 & 668 & 795 & 848 & 890 & 860 & 85 & 4188 \\
\hline 24 & & & & & & & 23 & 678 & 806 & 862 & 897 & 855 & $4|2|$ \\
\hline 25 & & & & & & & & 33 & 647 & 805 & 856 & 893 & 3234 \\
\hline 26 & & & & & & & & & 31 & 629 & 784 & 855 & 2299 \\
\hline 27 & & & & & & & & & & 16 & 613 & 798 & 1427 \\
\hline 28 & & & & & & & & & & & 10 & 633 & 643 \\
\hline
\end{tabular}

Notes: *We used 12 rounds of the NLSY97 data across 12 years from 1997 to 2008, which allows this analysis to examine developmental trajectories in the likelihood of overweight across 17 years from 12 to 28 years of age. The NLSY97 is an ongoing longitudinal panel study that contains a national representative sample of youth $12-16$ years of age by the end of 1996. The baseline survey was started in 1997 and follow-up surveys are conducted annually thereafter. The NLSY 97 contains a supplementary ethnic minority sample (predominantly non-Hispanic blacks, Hispanics). To better represent the condition in the nation, participants of this supplementary sample were not included in this analysis. 
the study sample, the variable race/ethnicity was included in trajectory modeling analysis to assess its impact on group membership and developmental trajectories.

Educational attainment was determined based on reported data of "the highest grade completed" by tracking participants from the baseline through all follow-up surveys. Participants were categorized into four groups (less than high school, high school, college, and post-college) for analysis with group 1 containing subjects who reported that their highest grade was middle school, group 2 whose highest grade was high school, group 3 whose highest grade was college, and group 4 whose highest schooling was any grades post-college. In addition to describing the sample, this variable was also used as an influential factor in trajectory analysis.

\section{Trajectory modeling}

We conducted the statistical analysis using SAS software (version 9.13; SAS Institute). The mixture growth model ${ }^{34}$ was used to detect latent subgroups with distinctive developmental trajectories. The modeling analysis was conducted using the PROC TRAJ procedure (SAS Institute). ${ }^{35}$ Before modeling analysis, data from the 12 years of survey from 1997 to 2008 were rearranged following the longitudinal design as described in Table 1 to cover an age span of 17 years from 12 to 28 years old. The likelihood of becoming overweight and obese over time/ages was modeled using PROC TRAJ. ${ }^{35}$ The Bayesian information criterion (BIC; adding one more group is associated with reductions in $\mathrm{BIC}$ for at least five units) ${ }^{35}$ was used to determine the number of subgroups. We used a threestep backward procedure established from our previous experience with this method ${ }^{36,37}$ to conduct the modeling analysis. Step 1, starting a model with a larger number of groups, all being set as cubic polynomial; Step 2, revising the model according to modeled results by reducing the number of groups and/or the order of specific polynomial of each group using BIC criteria and significant test of the estimated model coefficients; and Step 3, inclusion of risk factors and covariates after a trajectory model was successfully established. Start values of the model parameters were applied in Step 3 analysis to ensure the established subgroup models from previous two steps of analysis after influential factors were introduced. ${ }^{35}$ We conducted the modeling analysis for males and females respectively to show the risk profile of weight gain across the life course considering developmental differences by sex during the adolescence-young adulthood period.

\section{Results \\ Sample statistics at baseline}

Among the 4119 participants, 2009 (48.8\%) were male and $2110(51.2 \%)$ were female with an average age of 14.7 (standard deviation $[\mathrm{SD}]=1.4$ ) years; 66.4\% were nonHispanic white, 16.4\% non-Hispanic black, 6.5\% Hispanic, and $10.7 \%$ other.

\section{Developmental trajectories of overweight}

Figure 1A presents the results from the developmental trajectory analysis for males regarding the likelihood to become overweight. Overall, seven groups with distinctive developmental trajectories were detected. These seven overweight risk groups (WG) were: (i) WG1, the middleschool age risk group (19.7\%) with the likelihood to become overweight reached 0.90 before the age of 16 years; (ii) WG2, the high-school age risk group (11.4\%) with the same likelihood of passing 0.10 before the age of 15 years reached 0.90 after the age of 18 years; (iii) WG3, the college-age risk group (12.6\%) with the likelihood passing 0.10 before the age of 18 years and reached 0.90 at the age of 21.5 years; (iv) WG4, the post-college age risk group (11.8\%) with the likelihood passing 0.10 prior to the age of 20 years and reached 0.90 by the age of 24 years; (v) WG5, the work-family formation-age risk group $(11.0 \%)$ with the likelihood passing 0.10 at the age of 23 years and progressively increasing up to 0.88 by the age of 28 years; (vi) WG6, the linear-growing risk group (6.2\%) with the likelihood starting at around $0.30-0.40$ between the age of 12-13 years and progressively increasing toward overweight at a speed of $0.02 \%$ per year; and (vii) WG7, the persistent low-risk group (27.3\%) with the likelihood $<0.01$ throughout. The percentage of subjects in the first five groups with excess high risk of being overweight accounted for $66.5 \%$ of the total sample and $91.5 \%$ of subjects who ever became overweight during the period from the age of 12 to 28 years old.

Seven distinct groups were also detected among females (Figure 1B), of which six were similar to those observed among males. These similar groups were: (i) WG1 (12.6\%, started weight gain at a higher level with quicker progression than males), (ii) WG2 (13.6\%, started at a younger age but increased slower than males), (iii) WG3 (9.1\%, increased slightly quicker than males), (iv) WG4 (10.0\%, almost identical to males), (v) WG5 (12.9\%, very similar to that for males), and (vi) WG7 (36.4\%, similar to males). Instead of a linear-growing trend as WG6 for males, the risk of females in group WG6 (5.4\%) was self-limiting, the likelihood of becoming overweight for this group progressively increased from below 0.10 before 15 years old, peaked at 0.50 at around 

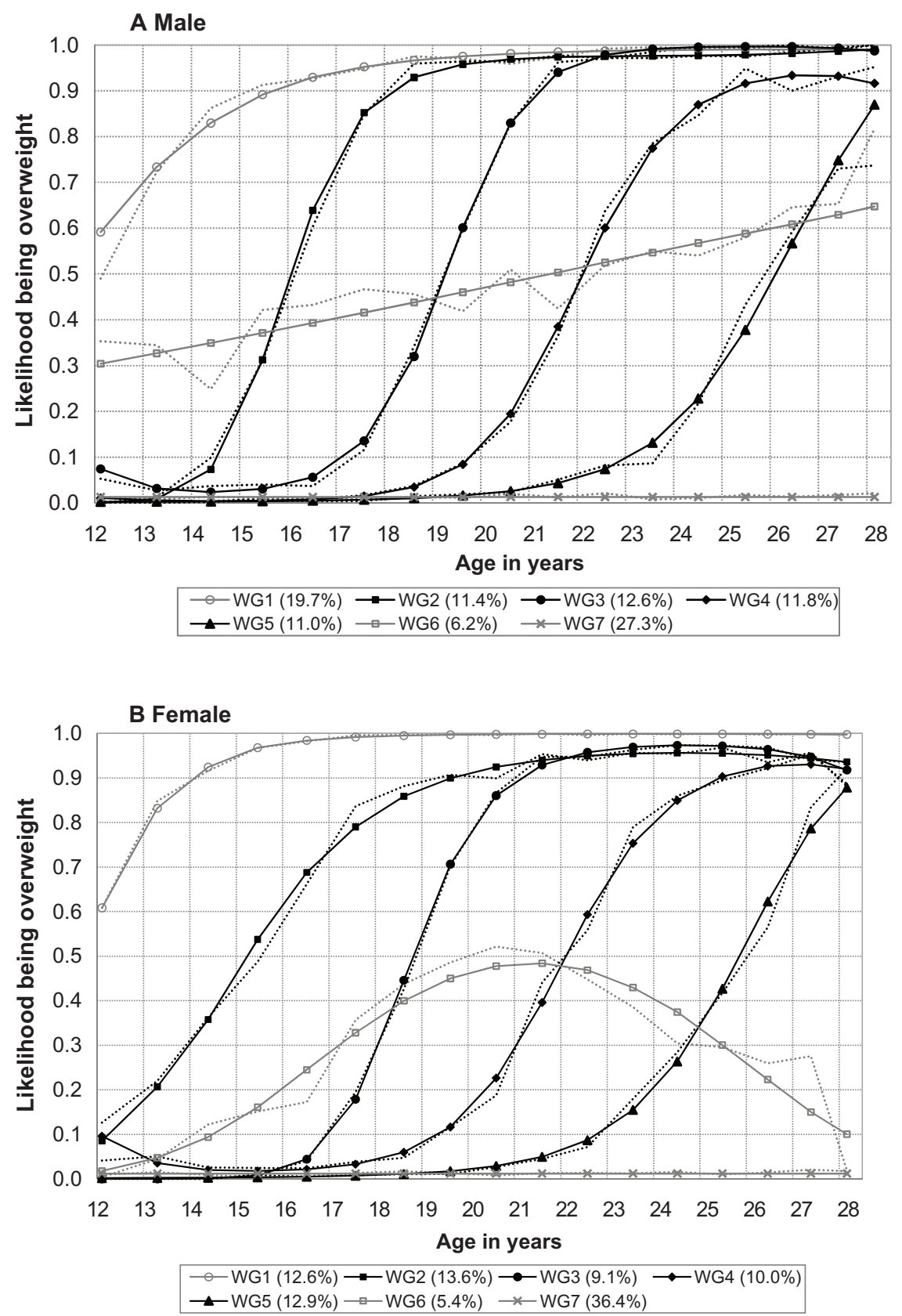

Figure I Trajectories of the likelihood to become overweight for US adolescents transitioning through emerging adulthood, the 1997-2008 National Longitudinal Survey of Youth 1997. (A) Male; (B) Female.

21-22 years old before it progressively declined, forming a bell-shaped curve. The first five groups with excess risk accounted for $58.2 \%$ of the total sample and $95.1 \%$ (coincidently the same as that for males) of those who ever became overweight from 12 to 28 years old.

\section{Developmental trajectories of obesity}

Figure $2 \mathrm{~A}$ presents the results from trajectory analysis modeling the likelihood to become obese among males. A total of six obese risk groups (OG) with distinctive likelihood trajectories were detected: OG1, middle-high school risk group (6.9\%); OG2, high school-college risk group (5.2\%); OG3, college- and post-college risk group (6.9\%); OG4, work and family-formation risk group (7.2\%); OG5, self-limiting risk group (4.8\%); and OG6, persistent low-risk group (68.9\%). Comparison of the obese trajectories with the overweight trajectories in Figure 1A indicate that four high-risk OG groups (OG1 through OG4) were corresponding with the four high-risk WG groups (WG1 through WG4) with a time delay of 1.5-2 years. 

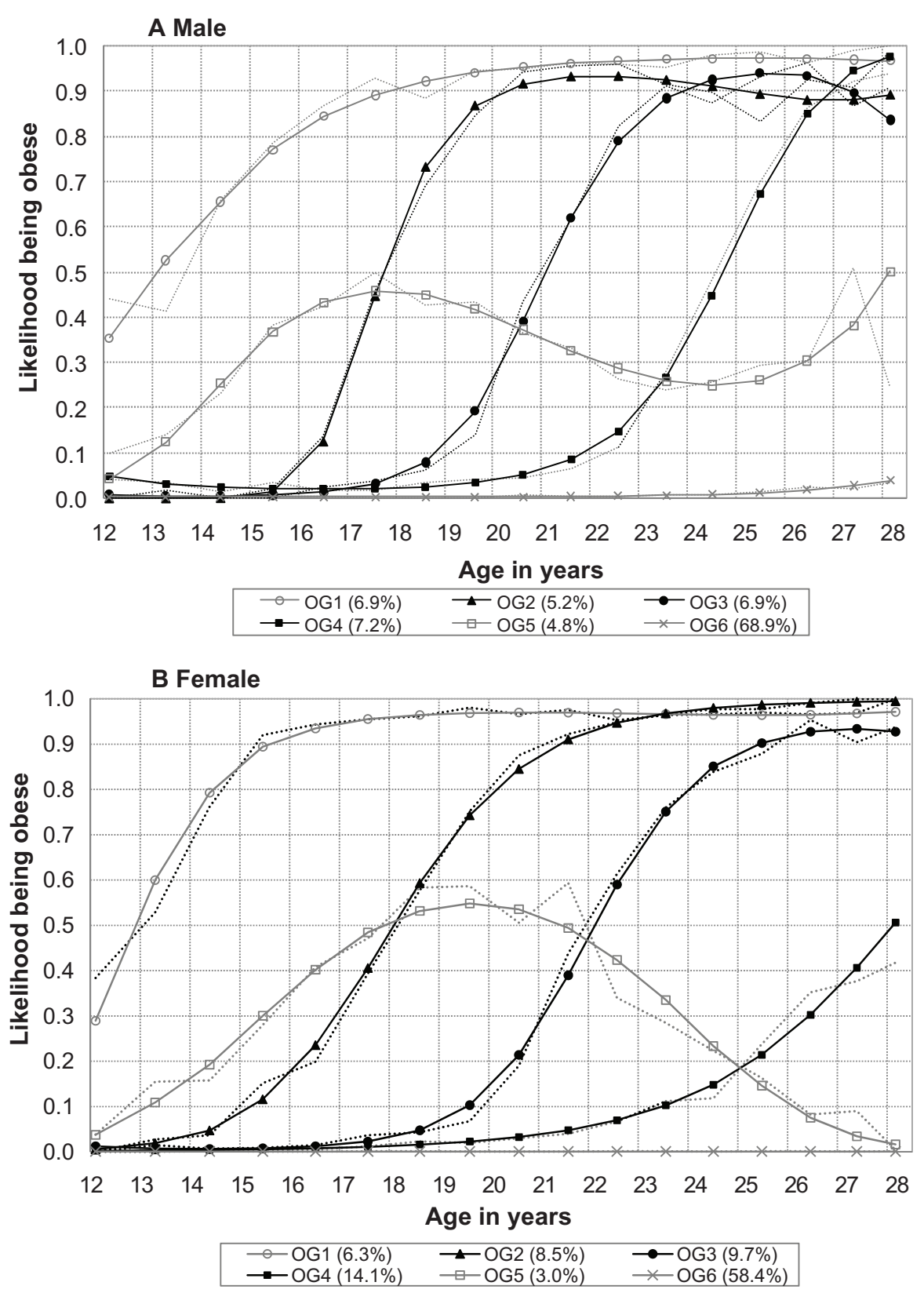

Figure 2 Trajectories of the likelihood to become obese for US adolescents transitioning through emerging adulthood, the 1997-2008 National Longitudinal Survey of Youth 1997. (A) Male; (B) Female.

Six obese risk groups were also detected among females (Figure 2B). Likewise, four (OG1 through OG4) of the six OG groups were related to the four WG groups (WG1 through WG4) as shown in Figure 1B. In addition, there were some sex differences in the trajectory patterns, particularly OG4 (work and family formation) and OG5 (self-limiting).

\section{Factors associated with overweight and obese}

Results from trajectory analysis indicated some associations of the two demographic factors (race and education) with the overweight (Table 2) and obese risk groups (Table 3), including the group memberships and the likelihood trajectories. For example, more education reduced the likelihood to be in the high-risk WG1 group for males (model coefficient $=-0.289$; $P<0.01)$ and being White increased the likelihood to be in WG1 for females (model coefficient $=1.329 ; P<0.01$ ).

\section{Discussion and conclusions}

In this study, we systematically modeled the likelihood of becoming overweight and obese among a national random sample of subjects across an age span of 17 years from 
Table 2 Influences (regression coefficients) of race/ethnicity and education attainment on group membership and developmental trajectories to become overweight from 12 through 28 years of age during 1997-2008, United States

\begin{tabular}{|c|c|c|c|c|c|c|c|c|}
\hline \multirow[t]{2}{*}{ Group } & \multicolumn{4}{|c|}{ Group membership } & \multicolumn{4}{|c|}{ Likelihood trajectory } \\
\hline & White & Black & Hispanic & Highest degree & White & Black & Hispanic & Highest grade \\
\hline \multicolumn{9}{|c|}{ Male $(\mathbf{N}=1989)$} \\
\hline WGI & $-0.585^{*}$ & -0.186 & 0.106 & $-0.289 * *$ & 0.095 & 0.004 & -0.104 & 0.003 \\
\hline WG2 & $-0.788 *$ & -0.285 & 0.388 & 0.114 & $2.164 * *$ & $1.199 * *$ & 0.857 & 0.086 \\
\hline WG3 & 0.116 & 0.531 & 0.671 & 0.158 & $1.501 *$ & $0.817 * *$ & 0.572 & 0.127 \\
\hline WG4 & 0.128 & -0.204 & 0.834 & 0.161 & $0.984^{*}$ & 0.525 & -0.397 & -0.011 \\
\hline WG5 & 0.217 & -0.027 & -1.553 & -0.126 & 0.012 & -0.586 & -3.762 & $-0.434^{*}$ \\
\hline WG6 & 1.050 & 0.930 & 1.130 & $-0.532 * *$ & $-1.278 * *$ & $-1.903^{* *}$ & -1.076 & -0.198 \\
\hline WG7 & ref & ref & ref & ref & 0.449 & $1.49 \mid$ & 1.270 & 0.056 \\
\hline \multicolumn{9}{|c|}{ Female $(\mathrm{N}=2097)$} \\
\hline WGI & $1.329 * *$ & $-1.346 * *$ & 0.478 & 0.363 & $2.326^{*}$ & $1.656 * *$ & 0.832 & -0.212 \\
\hline WG2 & 0.377 & 0.366 & 0.954 & 1.220 & $1.705 * *$ & I.147* & 0.965 & $0.619 * *$ \\
\hline WG3 & -0.661 & -0.334 & 0.030 & 0.216 & 0.078 & 0.429 & -0.587 & -0.021 \\
\hline WG4 & -0.985 & 0.533 & I.187* & 1.825 & 0.084 & I.107 & -0.846 & 0.218 \\
\hline WG5 & $-1.517^{*}$ & -0.155 & 0.734 & 1.434 & 0.550 & 0.940 & -2.832 & $-0.453^{*}$ \\
\hline WG6 & 0.262 & -0.219 & -0.224 & 0.620 & 0.850 & 0.486 & 0.063 & 0.179 \\
\hline WG7 & ref & ref & ref & ref & 0.897 & 1.334 & 1.573 & 0.180 \\
\hline
\end{tabular}

Notes: $* P<0.05 ; * * p<0.01$.

Data source: The National Longitudinal Survey of Youth 1997 NLSY97, 1997-2008.

Abbreviations: WG, overweight risk group; WGI, middle-school age risk group; WG2, high-school age risk group; WG3, college-age risk group; WG4, post-college age risk group; WG5, working and family formation-age group; WG6, linear growing risk for male and self-limiting risk for female; WG7, zero risk group; ref, reference group.

12 to 28 years old. This is a critical period characterized with rapid and unevenly paced changes and developments in the life course. Data used for this analysis were derived from the NLSY97, a valuable source with annual longitudinal data collection. Using the developmental trajectory analysis method, we detected seven overweight risk subgroups (WG) and six obese risk subgroups (OG) for males and females, respectively. The subgroups are characterized with distinctive group membership probabilities and developmental trajectories. Furthermore, the identified groups with increased risk to develop overweight and obese are closely related to key events in the life course during the period, and the risk groups are less likely to be affected by race/ethnicity and educational attainment.

Table 3 Influences of race/ethnicity and education attainment on group membership and developmental trajectories to become obese from 12 through 28 years of age during 1997-2008, United States

\begin{tabular}{|c|c|c|c|c|c|c|c|c|}
\hline \multirow[t]{2}{*}{ Group } & \multicolumn{4}{|c|}{ Group membership } & \multicolumn{4}{|c|}{ Likelihood trajectory } \\
\hline & White & Black & Hispanic & Highest degree & White & Black & Hispanic & Highest grade \\
\hline \multicolumn{9}{|c|}{ Male $(\mathbf{N}=1989)$} \\
\hline OGI & -0.470 & -0.036 & 0.025 & $-0.589 * *$ & $-0.930 *$ & -0.718 & $-0.8 \mid 4$ & 0.401 \\
\hline OG2 & 0.003 & -0.037 & 0.616 & 0.007 & -0.949 & -1.001 & -1.188 & -0.019 \\
\hline OG3 & -0.353 & -0.233 & -0.530 & -0.178 & $-1.442 * *$ & $-2.27 I^{* *}$ & -1.695 & 0.051 \\
\hline OG4 & $-0.644^{*}$ & -0.333 & -0.246 & -0.299 & -0.540 & $-1.001 *$ & 0.254 & 0.167 \\
\hline OG5 & -0.453 & 0.066 & -0.483 & -0.282 & $-0.854 * *$ & $-0.70 I^{*}$ & -0.530 & 0.033 \\
\hline OG6 & ref & ref & ref & ref & 0.161 & 1.019 & $1.419 *$ & -0.068 \\
\hline \multicolumn{9}{|c|}{ Female ( $N=2097)$} \\
\hline OGI & 0.227 & 3.624 & 0.840 & $-0.928 * *$ & -0.072 & $-0.565^{*}$ & 0.058 & $0.889^{* *}$ \\
\hline OG2 & -0.449 & 2.234 & -0.222 & $-0.729 * *$ & -0.689 & $-1.176^{*}$ & -0.540 & 0.096 \\
\hline OG3 & -0.404 & 2.150 & -0.897 & $-0.633 * *$ & -0.061 & $-0.960 *$ & -0.192 & -0.042 \\
\hline OG4 & 0.176 & 3.620 & 0.561 & $-0.520 * *$ & 1.145 & -0.78 I & 0.474 & -0.206 \\
\hline OG5 & -0.738 & 2.332 & $-0.77 \mid$ & $-0.932^{* *}$ & 0.698 & 0.692 & 0.393 & 0.186 \\
\hline OG6 & ref & ref & ref & ref & -3.511 & -0.050 & -3.039 & -0.503 \\
\hline
\end{tabular}

Notes: $* p<0.05 ; * * p<0.01$.

Data source: The National Longitudinal Survey of Youth 1997 NLSY97, 1997-2008.

Abbreviations: OG, obesity risk group; ref, reference group. 


\section{High-risk groups across life course}

Findings of our study confirmed the conclusion from previous studies that subgroups exist with distinctive developmental trajectories in BMI measures. ${ }^{25,29,31,32}$ In addition to such findings, results from our study demonstrate that the risk for extra weight gain is life-course linked. Among the seven WG subgroups, five were closely related to specific age periods, WG1 with increased risk during the middle school ages, WG2 with increased risk during the high school ages, WG3 with increased risk during the college ages, WG4 with increased risk during the post-college ages, and WG5 with increased risk during the work and family-formation ages. Corresponding to the first four high-risk groups from WG1 to WG4, four high-risk obese groups were found. This finding further supports the existence of life course-related subgroups with distinctive patterns of risks for weight gain. Although a number of studies explored time patterns in weight gain using samples across various age spans from birth to adulthood, ${ }^{1,17,24,26,27,29,30,32,38}$ findings from our study add additional meaning for us to understand life course-linked risk for overweight and obesity. The finding of the five high risk WG groups suggests the need for five consecutive bodyweight tests during the life course. Only if a person passes all five tests, can he or she be risk-free from becoming overweight or obese.

\section{Implementations for prevention intervention}

First, findings of this study indicated that only a small portion of US adolescents ( $27.3 \%$ of males and $36.4 \%$ of females) can pass the "five tests" through their young adulthood without become overweight and obese. The majority fail the tests. To prevent people from becoming overweight, long-term effort is required at various levels from the nation to communities, families, schools, and individual Americans. Second, targeting high-risk groups by stages in life course could be an ideal strategy for prevention. Findings of our study indicate that at each of the five periods from 12 to 28 years of age, there is a group of subjects who are vulnerable to become overweight and obese. Theoretically, programs may become more efficient and cost-effective by emphasizing strategies to target these at-risk subjects.

\section{Implication for etiological study}

Findings of subgroups at risk for becoming overweight and obese at various periods provide a basis supporting studies to examine modifiable factors associated with each risk group. Such studies will provide the data necessary for targeted intervention. As an individual matures from middle school through college, he or she shifts away from the situation where they may consume what the family or school provides, to foods of self-preference (typically those high in calories), ${ }^{39-42}$ from enjoying a naturally balanced movement and sleep lifestyle to sleeping more and moving less, ${ }^{40,41,43}$ and from passively copying peers to actively following role models, ${ }^{44-46}$ as commonly observed in the United States. After completion of the school education, changes related to employment and family formation may also result in new risk for weight gain, such as marriage, ${ }^{2,47}$ pregnancy and birth of children in women ${ }^{48-50}$ family and work-related stress, and sedentary work.

In addition to the lifestyle-related risk factors described above, it is also likely that individuals may genetically differ in susceptibility to proweight-gain risks at different periods in life. ${ }^{51,52}$ The detected risk groups were not closely related to race and education, implying the potential interaction of internal biological processes and the living environment. Genetic epidemiological studies suggest that genes, environment and the interaction between the two play a key role in weight gain. ${ }^{53,54}$ Further studies are needed to investigate interactions between genetic factors and life course-linked factors to advance our understanding of the development of overweight and obesity. It is quite likely that the observed risk groups resulted from an interaction between the intrinsic susceptibility to weight gain determined by genes and the life course-linked factors during each of the key five periods.

\section{Limitations}

There are several limitations to this study. First, findings we reported in this study were derived using the data among participants who completed all 12 waves of surveys. Although our analysis indicated no difference in BMI assessed at baseline between those who were retained in the study and who were lost to follow-up; developmental trajectories of these participants could not be assessed. Second, the cut-off points $\left(\right.$ BMI $>25 \mathrm{~kg} / \mathrm{m}^{2}$ for overweight and BMI $>30 \mathrm{~kg} / \mathrm{m}^{2}$ ) for adults were used for participants aged 12-17 years as a proxy. If the Centers for Disease Control and Preventionrecommended cut-off points for children ${ }^{55,56}$ were used, a discontinuity appeared in the estimated risk trajectory before and after the age of 17 years. Despite the fact that adolescents in this age range are physically more close to an adult than to a young child, the issues of misclassification could not be ruled out without more concrete standard, such as dual energy X-ray absorptiometry scans for an objective assessment of excess body fat. Lastly, data from birth to 12 years of age are not available from the NLSY97, which 
prevented us from investigating a completed trajectory patterns starting from birth. Despite these limitations, this study is the first to model the likelihood of becoming overweight and obese rather than BMI measures with a national and random representative sample. Findings of this study add new data regarding life-course linked risk of overweight gain, and provide fundamental data supporting hypothesis formation to examine risk factors and to devising prevention intervention programs with focus on more specific periods during the life course.

\section{Acknowledgments}

This research was supported in part by NIH 1U01HL097889-01 and the Department of Pediatrics, Wayne State University. The authors thank Mrs Yifan Jiang for her dedicated work in processing data from the NLSY97 and participation in the developmental trajectory modeling analysis.

\section{Disclosure}

The authors declare no conflict of interests in this work.

\section{Reference}

1. Lee JM, Pilli S, Gebremariam A, et al. Getting heavier, younger: trajectories of obesity over the life course. Int J Obes (Lond). 2010;34:614-623.

2. Koball H, Moiduddin E, Henderson J, Goesling B, Besculides M. What do we know about the link between marriage and health? J Fam Issues. 2010;31:1019-1040.

3. Daniels SR. The consequences of childhood overweight and obesity. Future Child. 2006;16:47-67.

4. Singh AS, Mulder C, Twisk JW, van Mechelen W, Chinapaw MJ. Tracking of childhood overweight into adulthood: a systematic review of the literature. Obes Rev. 2008;9:474-488.

5. Johannsson E, Arngrimsson SA, Thorsdottir I, Sveinsson T. Tracking of overweight from early childhood to adolescence in cohorts born 1988 and 1994: overweight in a high birth weight population. Int $J$ Obes (Lond). 2006;30:1265-1271.

6. Thomas C, Hypponen E, Power C. Obesity and type 2 diabetes risk in midadult life: the role of childhood adversity. Pediatrics. 2008;121:e1240-e1249.

7. Goran MI, Ball GD, Cruz ML. Obesity and risk of type 2 diabetes and cardiovascular disease in children and adolescents. J Clin Endocrinol Metab. 2003;88:1417-1427.

8. Flegal KM, Graubard BI, Williamson DF, Gail MH. Excess deaths associated with underweight, overweight, and obesity. JAMA. 2005;293:1861-1867.

9. Flegal KM, Graubard BI, Williamson DF, Gail MH. Cause-specific excess deaths associated with underweight, overweight, and obesity. JAMA. 2007;298:2028-2037.

10. Romero-Corral A, Montori VM, Somers VK, et al. Association of bodyweight with total mortality and with cardiovascular events in coronary artery disease: a systematic review of cohort studies. Lancet. 2006;368:666-678.

11. Harris KM, Perreira KM, Lee D. Obesity in the transition to adulthood: Predictions across race/ethnicity, immigrant generation, and sex. Arch Pediatr Adolesc Med. 2009;163:1022-1028.

12. Gordon-Larsen P, Adair LS, Nelson MC, Popkin BM. Five-year obesity incidence in the transition period between adolescence and adulthood: the National Longitudinal Study of Adolescent Health. Am J Clin Nutr. 2004;80:569-575.
13. Arnett JJ. Conceptions of the transition to adulthood: Perspectives from adolescence through midlife. J Adult Dev. 2001;8:133-143.

14. Wethington E. An overview of the life course perspective: implications for health and nutrition. J Nutr Educ Behav. 2005;37:115-120.

15. Arnett JJ. Emerging adulthood. A theory of development from the late teens through the twenties. Am Psychol. 2000;55:469-480.

16. Adair LS. Child and adolescent obesity: epidemiology and developmental perspectives. Physiol Behav. 2008;94:8-16.

17. Li C, Goran MI, Kaur H, Nollen N, Ahluwalia JS. Developmental trajectories of overweight during childhood: role of early life factors. Obesity (Silver Spring). 2007;15:760-771.

18. Burt Solorzano CM, McCartney CR. Obesity and the pubertal transition in girls and boys. Reproduction. 2010;140:399-410.

19. Scharoun-Lee M, Adair LS, Kaufman JS, Gordon-Larsen P. Obesity, race/ethnicity and the multiple dimensions of socioeconomic status during the transition to adulthood: A factor analysis approach. Soc Sci Med. 2009;68:708-716.

20. Guo SS, Roche AF, Chumlea WC, Gardner JD, Siervogel RM. The predictive value of childhood body mass index values for overweight at age 35 y. Am J Clin Nutr. 1994;59:810-819.

21. Dietz WH. Critical periods in childhood for the development of obesity. Am J Clin Nutr. 1994;59:955-959.

22. Jacobsen BK, Njolstad I, Thune I, Wilsgaard T, Lochen ML, Schirmer H. Increase in weight in all birth cohorts in a general population: The Tromso Study, 1974-1994. Arch Intern Med. 2001;161:466-472.

23. Nader PR, O'Brien M, Houts R, et al. Identifying risk for obesity in early childhood. Pediatrics. 2006;118:e594-e601.

24. Wells NM, Evans GW, Beavis A, Ong AD. Early childhood poverty, cumulative risk exposure, and body mass index trajectories through young adulthood. Am J Public Health. 2010;100:2507-2512.

25. Baltrus PT, Lynch JW, Everson-Rose S, Raghunathan TE, Kaplan GA. Race/ethnicity, life-course socioeconomic position, and body weight trajectories over 34 years: the Alameda County Study. Am J Public Health. 2005;95:1595-1601.

26. Chivers P, Hands B, Parker H, Beilin L, Kendall G, Bulsara M. Longitudinal modelling of body mass index from birth to 14 years. Obes Facts. 2009;2:302-310.

27. Dai S, Labarthe DR, Grunbaum JA, Harrist RB, Mueller WH. Longitudinal analysis of changes in indices of obesity from age 8 years to age 18 years. Project HeartBeat! Am J Epidemiol. 2002;156:720-729.

28. Lewis CE, Jacobs DR Jr, McCreath $\mathrm{H}$, et al. Weight gain continues in the 1990s: 10-year trends in weight and overweight from the CARDIA study. Coronary Artery Risk Development in Young Adults. Am J Epidemiol. 2000;151:1172-1181.

29. Ostbye T, Malhotra R, Landerman LR. Body mass trajectories through adulthood: results from the National Longitudinal Survey of Youth 1979 Cohort (1981-2006). Int J Epidemiol. 2010;40:240-250.

30. Mustillo S, Worthman C, Erkanli A, Keeler G, Angold A, Costello EJ. Obesity and psychiatric disorder: developmental trajectories. Pediatrics. 2003;111:851-859.

31. Nonnemaker JM, Morgan-Lopez AA, Pais JM, Finkelstein EA. Youth BMI trajectories: evidence from the NLSY97. Obesity (Silver Spring). 2009; 17:1274-1280.

32. Ventura AK, Loken E, Birch LL. Developmental trajectories of girls' BMI across childhood and adolescence. Obesity (Silver Spring). 2009;17:2067-2074.

33. Goodwin P, McGill B, Chandra A. Who marries and when? Age at first marriage in the United States: 2002. NCHS Data Brief. 2009:1-8.

34. Nagin DS. Analyzing developmental trajectories: A semiparametric, group-based approach. Psychol Methods. 1999;4:139-157.

35. Jones BL, Nagin DS, Roeder K. A SAS procedure based on mixture models for estimating developmental trajectories. Sociol Methods Res. 2001;29:374-393.

36. Chen X, Lunn S, Deveaux L, et al. A cluster randomized controlled trial of an adolescent HIV prevention program among Bahamian youth: effect at 12 months post-intervention. AIDS Behav. 2009;13:499-508. 
37. Chen X, Naar-King S, Murphy D, Parson JT. A clinic-based motivational intervention improves condom use among subgroups of youth living with HIV-A multicenter randomized controlled trial. J Adolesc Health. 2011;49:193-198.

38. Clarke P, O’Malley PM, Johnston LD, Schulenberg JE. Social disparities in BMI trajectories across adulthood by gender, race/ethnicity and lifetime socio-economic position: 1986-2004. Int J Epidemiol. 2009;38:499-509.

39. Cuevas-Nasu L, Hernandez-Prado B, Shamah-Levy T, Monterrubio EA, Morales-Ruan Mdel C, Moreno-Macias LB. Overweight and obesity in school children aged 5 to 11 years participating in food assistance programs in Mexico. Salud Publica Mex. 2009;51(Suppl 4):S630-S637.

40. Davy BM, Harrell K, Stewart J, King DS. Body weight status, dietary habits, and physical activity levels of middle school-aged children in rural Mississippi. South Med J. 2004;97:571-577.

41. Gable S, Chang Y, Krull JL. Television watching and frequency of family meals are predictive of overweight onset and persistence in a national sample of school-aged children. J Am Diet Assoc. 2007;107:53-61.

42. Sira N, Pawlak R. Prevalence of overweight and obesity, and dieting attitudes among Caucasian and African American college students in Eastern North Carolina: A cross-sectional survey. Nutr Res Pract. 2010;4:36-42.

43. Powell LM, Han E, Chaloupka FJ. Economic contextual factors, food consumption, and obesity among US adolescents. J Nutr. 2010;140:1175-1180.

44. Desai MN, Miller WC, Staples B, Bravender T. Risk factors associated with overweight and obesity in college students. J Am Coll Health. 2008;57:109-114

45. Haug E, Rasmussen M, Samdal O, et al. Overweight in school-aged children and its relationship with demographic and lifestyle factors: results from the WHO-Collaborative Health Behaviour in Schoolaged Children (HBSC) study. Int J Public Health. 2009;54(Suppl 2): 167-179.
46. Humenikova L, Gates GE. Social and physical environmental factors and child overweight in a sample of American and Czech school-aged children: a pilot study. J Nutr Educ Behav. 2008;40:251-257.

47. Mullan Harris K, Hedwig Lee, DeLeone FY. Marriage and health in the transition to adulthood: Evidence for African Americans in the Add Health Study. J Fam Issues. 2010;31:1106-1143.

48. Mamun AA, Kinarivala M, O’Callaghan MJ, Williams GM, Najman JM, Callaway LK. Associations of excess weight gain during pregnancy with long-term maternal overweight and obesity: evidence from $21 \mathrm{y}$ postpartum follow-up. Am J Clin Nutr. 2010;91:1336-1341.

49. Amorim AR, Rossner S, Neovius M, Lourenco PM, Linne Y. Does excess pregnancy weight gain constitute a major risk for increasing long-term BMI? Obesity (Silver Spring). 2007;15:1278-1286.

50. Rooney BL, Schauberger CW. Excess pregnancy weight gain and longterm obesity: one decade later. Obstet Gynecol. 2002;100:245-252.

51. Koeppen-Schomerus G, Wardle J, Plomin R. A genetic analysis of weight and overweight in 4-year-old twin pairs. Int J Obes Relat Metab Disord. 2001;25:838-844.

52. Wardle J, Carnell S, Haworth CM, Plomin R. Evidence for a strong genetic influence on childhood adiposity despite the force of the obesogenic environment. Am J Clin Nutr. 2008;87:398-404.

53. Duncan AE, Agrawal A, Grant JD, Bucholz KK, Madden PA, Heath AC. Genetic and environmental contributions to BMI in adolescent and young adult women. Obesity (Silver Spring). 2009;17:1040-1043.

54. Tholin S, Rasmussen F, Tynelius P, Karlsson J. Genetic and environmental influences on eating behavior: the Swedish Young Male Twins Study. Am J Clin Nutr. 2005;81:564-569.

55. Cole TJ, Bellizzi MC, Flegal KM, Dietz WH. Establishing a standard definition for child overweight and obesity worldwide: international survey. BMJ. 2000;320:1240-1243.

56. Kuczmarski RJ, Ogden CL, Guo SS. 2000 CDC growth charts for the United States: Methods and development. Vital Health Stat. 2002;11: $10-15$.
Adolescent Health, Medicine and Therapeutics

\section{Publish your work in this journal}

Adolescent Health, Medicine and Therapeutics is an international, peer-reviewed, open access journal focusing on health, pathology, and treatment issues specific to the adolescent age group. All aspects of health maintenance, preventative measures and disease treatment interventions are addressed within the journal and practitioners from

\section{Dovepress}

all disciplines are invited to submit their work as well as healthcare researchers and patient support groups.. The manuscript management system is completely online and includes a very quick and fair peerreview system. Visit http://www.dovepress.com/testimonials.php to read real quotes from published authors. 